\title{
Mapping and Validation of Quantitative Trait Loci for Root Architectural Traits in Rice (Oryza sativa) under Non-Stress and Salinity Stress Conditions
}

\author{
D.R. Gimhani, B.P. Abhayawickrama, M.S.F. Saliha and N.S. Kottearachchi ${ }^{1}$
}

Department of Biotechnology

Faculty of Agriculture and Plantation Management

Wayamba University of Sri Lanka

Sri Lanka

\begin{abstract}
Root architectural traits are governed by many genes exhibiting polygenic inheritance. The dissection of the genetic basis of root traits could be achieved by mapping of quantitative trait loci (QTLs) using molecular markers. The present study was conducted aiming at identifying root QTLs in rice using a recombinant inbred line (RIL) population derived from At354 and Bg352. At354 has less extensive, thin root structure and Bg352 has apparently large extensive, dense root structure. Ninety one RILs were phenotypically assessed for root traits namely, root volume $(R V)$, top root girth (TRG), root dry weight $(R D W)$ and root length $(R L)$ under hydroponics. Frequency distributions of these traits indicated broad spectrum of genetic variability in the RIL population. Quantitative Trait Loci (QTLS) were mapped using Single Nucleotide Polymorphism (SNP) markers investigated from a previous study corresponding to same RILs. Results revealed eight QTLs associated with TRG and RDW explaining phenotypic variation ranging from $8.3 \%$ to $14.8 \%$ under non-stress hydroponics. Identified root QTLs were located within the narrow flanking SNP marker intervals of chromosome 2, 4, 5, 7, 8 and 10. Of them, six root QTLs were colocalized exactly within the same flanking regions of previously identified root QTLs under salinity stress, indicating their contribution under both stress and non-stress conditions. The same donor alleles have contributed in both set of QTLs and these results validated and confirmed the fidelity of the QTLs detected on TRG and RDW. Moreover, this study found a closely associated, user friendly, simple sequence repeat marker, RM24894 to the QTL qNTRG10 and qNRDW10 which could facilitate marker assisted breeding.
\end{abstract}

Keywords: Quantitative trait loci, rice, root traits

\section{INTRODUCTION}

Rice (Oryza sativa L.) is the staple food for more than half of the world's population. Therefore, in order to fulfil the global demand for rice in line with the increment of world's population, it is necessary to increase rice production by producing rice varieties with higher yield potential and greater yield stability than conventional varieties. Rice yield is highly influenced by root traits as it affects for the degree of absorption of water and mineral nutrients. Moreover, a deep, thick and more branched root system with a high root to shoot ratio greatly facilitates its survival under abiotic stress conditions such as drought and salinity (Fukai and Cooper, 1995; Gowda et al., 2011). Accordingly, rice breeding programs

\footnotetext{
${ }^{1}$ Corresponding author: kottearachchins@yahoo.com
} 
have focused to develop rice varieties with improved root architecture, which would enhance the yield potential and yield stability in rice.

Rice root development traits are controlled by many genes exhibiting the quantitative or polygenic inheritance of the traits. Dissection of the genetic basis for root system architecture could be achieved by mapping of quantitative trait loci (QTLs) of root traits using molecular markers. Several QTL mapping studies have been undertaken to identify QTLs associated with various root related traits (Steele et al., 2006; Bing-Song et al., 2006; Mai et al., 2014; Lou et al., 2015).

In the present study, two improved rice varieties belonging to 3.5 months age class, namely, At354 and Bg352, were selected as parents since they show vast differences in their root traits. Although, At354 is considered as favourable for salinity tolerance, the exact root architectural trait that it contributes towards salinity tolerance has not been specifically studied to-date. Maiti (2012) reported that plants adapted to saline soil demonstrate more number of profuse lateral roots spreading superficially for osmotic adjustment and deep tap root for absorbing low concentrated soil water from deeper layers of the soil if upper soil is enriched with saline water. Only few studies have linked root architectural responses to salinity stress tolerance and therefore, this study was undertaken with the objective of understanding root architectural response in relation to saline stress and non-stress conditions via QTL mapping of root traits. Gimhani et al. (2014) has developed a RIL (recombinant inbred line) population from At354 and $\mathrm{Bg} 352$. In the present study, sub set of previously developed RIL population $\left(\mathrm{F}_{6}\right)$ was used to map genes/QTLs for few root traits under normal growth conditions. The root QTLs revealed under salinity stress condition (Gimhani et al., 2016), using the same mapping population, were also used to recognize consistent QTLs under both environmental conditions. This paper reports procedure involved in mapping QTLs for some traits of root system architecture and, the details of consistent genomic regions governing root architectural traits in non-stress and salinity stress condition, which would facilitate future rice breeding programmes towards higher yield potential.

\section{MATERIALS AND METHODS}

\section{Plant material}

This study used a RIL population containing 91 RILs selected from the 281 RILs derived from the At354 and $\mathrm{Bg} 352$ cross based on superiority and inferiority performances of salinity tolerance (Gimhani et al., 2014). By appearance, At354 showed less extensive, thin root structure while Bg352 showed an extensive and dense root structure (Figure 1). 


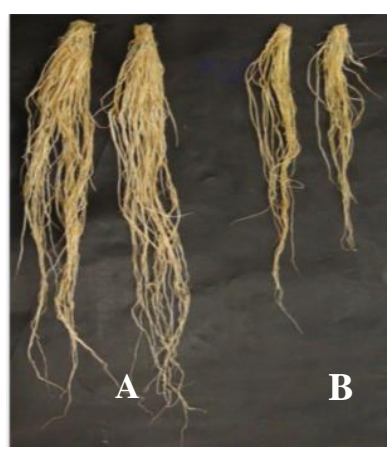

Figure1.Root trait differences between 7 weeks old At354 (B) and Bg352 (A) grown under hydroponics (non-stress condition)

\section{Assessment of root phenotypes in hydroponics}

The experiment was set up in a Randomized Complete Block Design (RCBD) with two blocks containing three plants from each line per block representing three replicates per RIL per block. Phenotypic assessment of root traits was done using all six plants from each RIL along with the parents. After germination, seedlings were transplanted to a hydroponic system supplemented with Yoshida nutrient solution (Yoshida et al., 1976). Fifty six days after transplanting, plants were uprooted and the root length (RL), root volume (RV), top root girth (TRG) and root dry weight (RDW) were measured. Root dry weight of the respective lines was recorded after oven drying the root samples at $80{ }^{\circ} \mathrm{C}$ until constant weight.

\section{Genotyping of the RIL population}

Genotypic data resulted with single nucleotide polymorphism (SNPs) markers with the same mapping population were obtained from our previous study (Gimhani et al., 2016), which used Illumina Infinium rice 6K SNP chip containing 5274 SNP loci covering all 12 rice chromosomes designed by Mark Wright and Susan McCouch of the Cornell University, USA (Thomson, 2014). Further, few simple sequence repeat (SSR) markers viz., four SSR markers on chromosome 2 (RM14065, RM14074, RM14102 and RM1397) and three SSR markers on chromosome 10 (RM24894, RM24903 and RM228) were also selected from the Gramene database (www.gramene.org) on the basis of their map locations for the genotyping of mapping population.

Genomic DNA was extracted from the three week-old seedlings of respective 91 RILs and two parents according to the method presented inhttp://rgp.dna.affrc.go.jp/J/rgp/protocols/ QTL.pdf. Two parents (At354 and Bg352) were screened for polymorphism using selected SSR markers. Polymerase chain reaction (PCR) was conducted using $12 \mu 1$ of PCR reaction mixture consisted of $5 \mu$ l of DNA sample, $1.2 \mu 1$ of 10X PCR buffer (Promega, USA), $1.2 \mu \mathrm{l}$ of dNTPs (2.5 mM of each dNTP) (Promega, USA), $0.8 \mu$ l of primer mixture ( $20 \mu \mathrm{M}$ of each Forward and Reverse primer; Integrated DNA Technologies, USA), $0.2 \mu$ l of Taq DNA polymerase $(5 \mathrm{U} / \mu \mathrm{l})$ (DreamTaq, Fermentas). Final volume of the reaction mixture was adjusted to $12 \mu \mathrm{l}$ using sterile distilled water. The PCR amplification was performed using BioRad (My CyclerTM) thermal cycler and amplification profile consisted of initial denaturation at $95{ }^{\circ} \mathrm{C}$ for $5 \mathrm{~min}$. followed by 35 cycles of denaturation at $95{ }^{\circ} \mathrm{C}$ for $1 \mathrm{~min}$, 
annealing at optimum temperature for $30 \mathrm{sec}$., extension at $72{ }^{\circ} \mathrm{C}$ for $1 \mathrm{~min}$. and final extension at $72{ }^{\circ} \mathrm{C}$ for $5 \mathrm{~min}$. The amplified PCR product was analysed by electrophoresis on $3 \%$ agarose gel stained with $0.5 \mu \mathrm{g} / \mathrm{ml}$ ethidium bromide. Polymorphic markers between parents (At354 and Bg352) were used for the genotyping of 91 RILs.

Manual scoring of alleles was done by comparing parental alleles as co-dominant markers. Based on the parental alleles, allelic band similar to At354 parental allele was designated as "A" genotype. Allelic band similar to Bg352 parental allele was designated as "B" genotype. Individuals with heterozygous genotype where both parental alleles were present at the respective SSR locus were designated as " $h$ ".

\section{Statistical analysis of root traits}

Root phenotypic data were analysed statistically using MINITAB V17.0 (Minitab17, 2010). All the measured root phenotypic traits of parents were compared with Student's t-test. The four root traits within the RIL population were subjected to Analysis of Variance (ANOVA). Frequency distributions of each root trait were plotted to examine the nature of variation in each trait within the RIL population. In addition, correlations between pairs of traits were also estimated by using the Pearson Correlation Coefficient $(P=0.05)$.

\section{Mapping of root QTLs}

The QTL analysis was performed using the phenotypic data on root traits and genotypic data of the 91 RILs by employing Composite Interval Mapping approach (CIM). Physical position $(\mathrm{Mb})$ of the SSR and SNP markers based on the Nipponbare genome was used as an approximate estimation of marker distances in centi Morgan (cM) by multiplying the physical position in $\mathrm{Mb}$ by a factor of 4 . For the estimation of genetic distances between markers for QTL mapping, one million bases on a rice chromosome were assumed to be equivalent to approximately $3.92 \mathrm{cM}$ (International Rice Genome Sequencing Project, 2005; Thomson et al., 2010; Ye et al., 2011; Sandhu et al., 2014). These cM positions were used for CIM. The CIM was performed by Qgene 4.3.10 (Joehanes and Nelson, 2008). Permutation test (1000 times) was performed for each trait to establish a LOD (Logarithm of odds) threshold value at the 0.05 significance level (Doerge and Churchill, 1996). The proportion of the observed phenotypic variance explained by each QTL was estimated by the Coefficient of Determination $\left(\mathrm{R}^{2}\right)$. Root QTLs that were identified under normal growth condition were compared with the previously mapped root related QTLs under salinity stress condition to reveal the validity and consistency of the QTLs in both environmental conditions.

\section{RESULTS AND DISCUSSION}

\section{Phenotypic variation of root traits}

According to the phenotypic variation of root traits, selected parents were significantly different $(P<0.05)$ for RV and RDW (Table 1). The frequency distributions of all four root traits across the mapping population showed continuous and near normal distribution (Figure 2 ), which lie down within the acceptable range of skeweness below +1.5 and above -1.5 (Tabachnick and Fidell, 2013) exhibiting quantitative nature of the measured traits (Table 1). Although RL and TRG were not significantly different $(P>0.05)$ between 2 parents, the 
variation of these two traits among RILs were significant $(P<0.001)$, indicating sufficient recombination events. Further, a higher coefficient of variation (CV) associated with each trait ranging from 15.2 to $35.8 \%$ indicated the exhibition of wide variation of all the traits among the RILs (Table 1). This observation was also supported by the results of ANOVA, which revealed highly significant differences among RILs $(P<0.001)$ for all the measured traits. Accordingly, present findings revealed the occurrence of substantial number of recombinants of parental genotypes with a broad spectrum of genetic variability of root related traits within the population, which would facilitate the QTL mapping for root traits.

Transgressive segregants were also observed in both directions indicating superior and inferior performances of certain RILs beyond parents (Table 1).

\begin{tabular}{|c|c|c|c|c|c|c|c|c|c|}
\hline \multirow[b]{2}{*}{ Trait } & \multicolumn{2}{|c|}{$\begin{array}{c}\text { Means of } \\
\text { parents }\end{array}$} & \multicolumn{6}{|c|}{ RIL Population } & \multirow{2}{*}{ 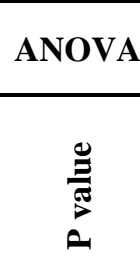 } \\
\hline & 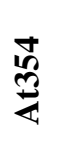 & 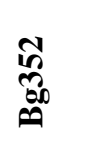 & 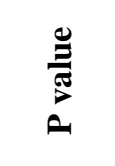 & $\sum_{\Sigma}^{\mathbb{J}}$ & $\equiv$ & $\sum^{\stackrel{u}{\Sigma}}$ & $\sum_{\infty}^{\infty}$ & 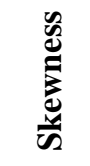 & \\
\hline $\mathrm{RL}$ & 30.0 & 30.5 & $0.870^{\mathrm{ns}}$ & 34.3 & 21.5 & 45.0 & 15.2 & -0.06 & $0.000 * *$ \\
\hline RV & 10.5 & 19.5 & $0.017 *$ & 16.4 & 2.3 & 32.5 & 30.8 & -0.10 & $0.016^{*}$ \\
\hline TRG & 5.2 & 5.8 & $0.455^{\mathrm{ns}}$ & 5.2 & 2.4 & 7.2 & 17.4 & -1.08 & $0.000 * * *$ \\
\hline RDW & 0.8 & 1.7 & $0.016^{*}$ & 1.2 & 0.1 & 2.3 & 35.8 & -0.30 & $0.000 * * *$ \\
\hline
\end{tabular}

Table 1. Phenotypic variation of root traits of two parents and RILs under non-stress condition

$R L$ - Root length, $R V$ - Root volume, TRG-Top root girth, $R D W$ - Root dry weight

${ }^{a} \mathrm{CV}$ - Coefficient of variation, * Significant at $P<0.05$, *** significant at $P<0.001,{ }^{n s}$ not significant $(P>0.05)$

\section{Correlation among root traits}

The correlation coefficient was calculated to detect inter-relationship between the measured root traits. Accordingly, all the studied root traits were significantly and positively correlated with each other (Table 2).

Table 2. Correlation of four root traits assessed in the RIL population under nonstress condition 


\begin{tabular}{cccc}
\hline & RV & TRG & RDW \\
\hline TRG & $0.419^{* * *}$ & & \\
RDW & $0.420^{* * *}$ & $0.862^{* *}$ & \\
RL & $0.195^{* *}$ & $0.270^{* * *}$ & $0.198^{* * *}$ \\
\hline
\end{tabular}
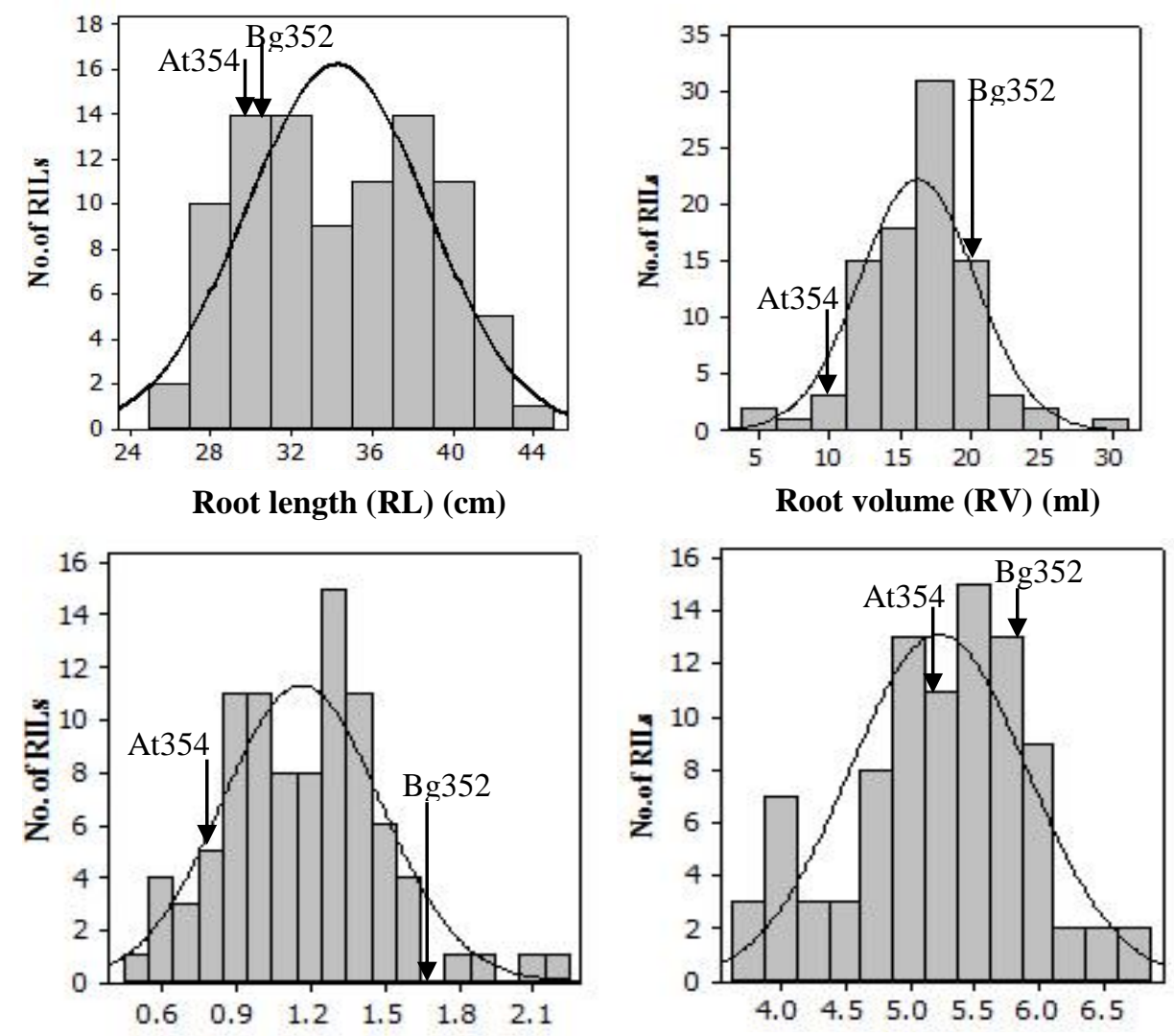

Root dry weight (RDW) (g)

Top root girth (TRG) $(\mathbf{c m})$

$R L$ - Root length, $R V$ - Root volume, TRG-Top Root Girth, RDW-Root Dry Weight; *significant at $P<0.05$, **significant at $P<0.01$, ***significant at $P<0.001$

Figure 2. Frequency distributions of root length, root volume, root dry weight and top root girth in the RIL population under non-stress condition

The mean values of At354 and Bg352 parents are indicated by arrows.

\section{Mapping of root QTLs}

The molecular maps comprising 1135 SNPs markers covering all 12 rice chromosomes (Gimhani et al., 2016) were used for the construction of QTL maps to locate root QTLs under normal growth condition. Parents were screened for polymorphism using four SSR markers on chromosome 2 and three SSR markers on chromosome 10 due to the fact that SSR markers are user friendly and convenient to use in marker assisted breeding than SNP markers. However, of them, only one SSR marker, RM24894, located on chromosome 10 showed polymorphism between parents in $3 \%$ agarose gel. Therefore, genotypic data were 
generated with 91 RILs using RM24894 marker and QTL map of chromosome 10 was reconstructed (Figure 3).

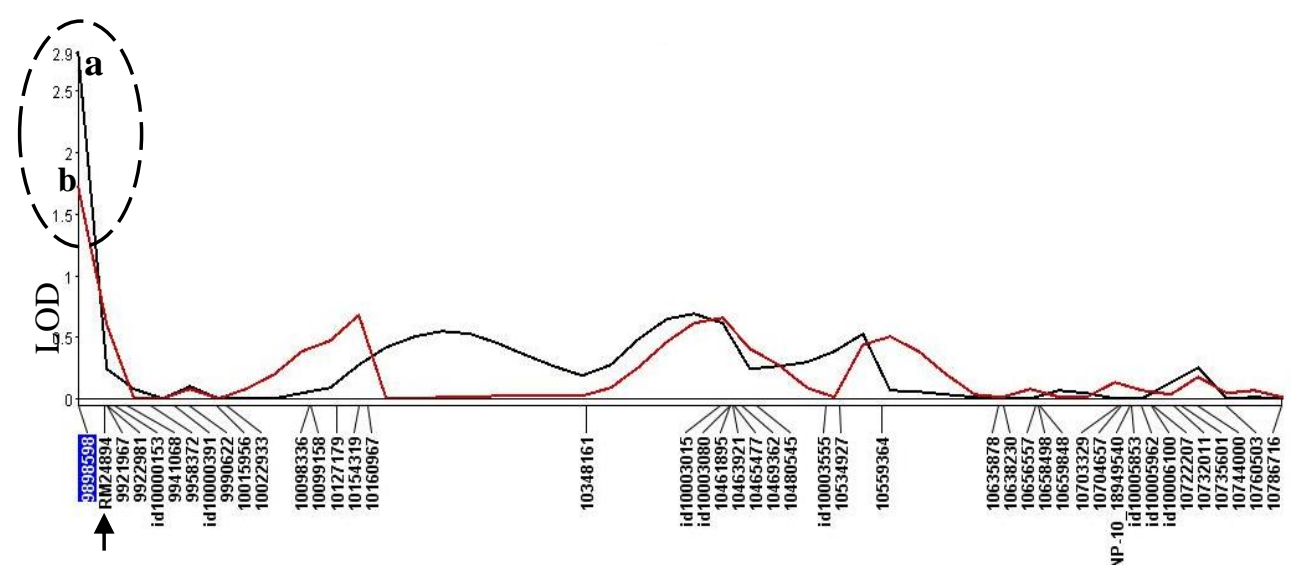

SNPs and SSR Marker positions

Figure 3. Co-localization of QTL maps of TRG and RDW on chromosome 10 under non-stress condition. A- QTL map of TRG b-QTL map of RDW

Circular area with dotted line indicates the co-localized $q T R G 10$ and $q R D W 10 \mathrm{QTL}$. Arrow head indicates the identified SSR marker closer to the $q T R G 10$ and $q R D W 10 \mathrm{QTL}$.

Based on the QTL analysis under non-stress condition, eight significant QTLs associated with top root girth (TRG) and root dry weight (RDW) explaining substantial proportion of phenotypic variation ranging from 8.3 to $14.8 \%$ were identified on chromosome $2,4,5,7,8$ and 10 (Table 3). A major QTL for TRG (qNTRG2) was detected explaining $12.1 \%$ of variation in the TRG under non-stress condition and, it is interesting to note that the QTL, $q N T R G 2$, was consistent with the $q R F W 2$ and $q R D W 2$ QTLs responsible for root fresh weight (RFW) and RDW identified under salinity stress condition, flanking the same genomic region of the chromosome $2(33.5-34.1 \mathrm{Mb}$ ) (Table $3 \&$ Figure 4). In addition, Lou et al. (2015) also identified a significant QTL for root depth in rice within the genomic region of 29.6-31.5 $\mathrm{Mb}$ on chromosome 2, which is closer to the present QTL location. Therefore, it could be suggested that identified QTL region on chromosome 2 would be a promising region of governing root related traits in rice.

Another major QTL for TRG ( $q N T R G 5$ ) under normal growth conditions was also identified on chromosome 5 explaining the highest phenotypic variation of $14.8 \%$ (Table 3). Similarly, our previous study revealed significant major QTL for RDW under salinity stress condition co-locating within the same flanking region on chromosome 5 (19.8-20.5 Mb) (Table 3 \& Figure 4). Both chromosome 7 and 10 also harbour major QTLs for TRG and RDW under non-stress condition, co-localizing with the RFW and RDW QTLs revealed under salinity stress condition within the same flanking region of the respective chromosome 7 (3.2-4.43 
$\mathrm{Mb})$ and $10(0.15-0.60 \mathrm{Mb})$ (Table 3 \& Figure 4). Lin et al., (2004) reported a QTL for root $\mathrm{K}^{+}$concentration under salinity stress flanking the region of $2.6-4.6 \mathrm{Mb}$ on chromosome 7 which is the same genomic region of qNTRG7 and $q N R D W 7$ QTLs identified in the present study. Though the QTLs of these two instances were identified on different root traits of two populations, it is likely to have common genes at this genome location affecting the root morphology and physiological functions.

Furthermore, the peak position of both qNTRG10 and qNRDW10 QTLs detected on chromosome 10 was at the same 9898598 SNP marker, demonstrating their promising nature (Figure 3). However, such SNP markers cannot be applied to introgress the QTL via marker assisted breeding (MAB) because of the high cost needs for technology. Therefore, this study was able to link a SSR marker with the peak SNP in order to facilitate MAB with this QTL.

Another significant putative QTL was identified on chromosome 8 for TRG ( $q N T R G 8$ ) under non-stress condition flanking the $25.30-25.75 \mathrm{Mb}$ genomic region. It was noted that $q N T R G 8$ QTL was closely associated with the flanking region of the $q R F W 8$ salt tolerant QTL located within the 27.81-28.06 $\mathrm{Mb}$ on chromosome 8 (Table 3). Another major putative QTL was also detected for RDW on chromosome 4 ( $q N R D W 4$ ) under normal growth conditions within the flanking region of 31.05-31.51 Mb. However, qNRDW4 QTL was not overlapped with the root QTLs detected under salinity stress condition (Table 3). Ahmadi and Fotokian (2011), detected a root QTL located within the region of 26.8-32.6 Mb of chromosome 4 which included in the same flanking region of $q N R D W 4$ of this study. Also Lou et al., (2015) have detected another QTL for deep rooting trait at the location of $28.4-29.1 \mathrm{Mb}$ on chromosome 4 . 
Table 3. Putative root related QTLs and their characterization under non-stress and salinity stress environmental conditions

\begin{tabular}{|c|c|c|c|c|c|c|c|c|c|c|c|c|}
\hline \multirow[t]{2}{*}{$\mathrm{Ch}^{\mathrm{a}}$} & \multirow[t]{2}{*}{ Trait } & \multirow{2}{*}{$\begin{array}{c}\text { Root } \\
\text { QTLs } \\
\text { (Under } \\
\text { Normal } \\
\text { growth) }\end{array}$} & \multirow{2}{*}{$\begin{array}{l}\text { Flanking } \\
\text { Marker/s }\end{array}$} & \multirow{2}{*}{$\begin{array}{l}\text { Flanking } \\
\text { region }\end{array}$} & \multirow{2}{*}{$\begin{array}{c}\text { Add. } \\
\text { Effect }^{\mathrm{b}}\end{array}$} & \multirow[t]{2}{*}{ LOD } & \multirow{2}{*}{$\begin{array}{l}\mathbf{R}^{2} \\
(\%)\end{array}$} & \multirow{2}{*}{$\begin{array}{l}\text { LOD } \\
\alpha=0.05\end{array}$} & \multirow[t]{2}{*}{$\mathbf{D A}^{\mathrm{c}}$} & \multicolumn{3}{|c|}{$\begin{array}{c}\text { Consistent root QTLS under } \\
\text { salinity stress }{ }^{\mathrm{d}} \\
\text { (Gimhani } \text { et al., 2016) }\end{array}$} \\
\hline & & & & & & & & & & QTL & $\begin{array}{c}\text { Flanking } \\
\text { region }\end{array}$ & $\mathbf{D A}^{\mathbf{c}}$ \\
\hline 2 & TRG & $q N T R G 2$ & $\begin{array}{l}2422788- \\
2437583 \text { SNPs }\end{array}$ & $\begin{array}{l}134.04-136.29 \\
\mathrm{cM}(\mathbf{3 3 . 5}-\mathbf{3 4 . 1} \\
\text { Mb) }\end{array}$ & 0.294 & 2.56 & 12.1 & 2.41 & $\mathrm{~A}$ & $\begin{array}{l}q R F W 2 q \\
R D W 2\end{array}$ & $\begin{array}{l}134.04- \\
136.29 \\
\mathrm{cM}(\mathbf{3 3 . 5}- \\
\mathbf{3 4 . 1} \mathbf{M b})\end{array}$ & $\mathrm{A}$ \\
\hline 4 & RDW & $q N R D W 4$ & $\begin{array}{l}\text { 4689325- } \\
4704444 \text { SNPs }\end{array}$ & $\begin{array}{l}124.21-126.04 \\
\mathrm{cM}(\mathbf{3 1 . 0 5 -} \\
\mathbf{3 1 . 5 1} \mathbf{M b})\end{array}$ & 0.146 & 2.78 & 13.1 & 2.56 & A & - & - & - \\
\hline 5 & TRG & $q N T R G 5$ & $\begin{array}{l}5525279- \\
\text { id5008590 } \\
\text { SNPs }\end{array}$ & $\begin{array}{l}\text { 79.25-82.20 } \\
\mathrm{cM}(\mathbf{1 9 . 8}-\mathbf{2 0 . 5} \\
\mathbf{M b )}\end{array}$ & 0.831 & 3.17 & 14.8 & 2.18 & A & $q R D W 5$ & $\begin{array}{l}79.25-82.20 \\
\mathrm{cM}(\mathbf{1 9 . 8}- \\
\mathbf{2 0 . 5} \mathbf{M b})\end{array}$ & A \\
\hline 7 & $\begin{array}{l}\text { TRG } \\
\text { RDW }\end{array}$ & $\begin{array}{l}q N T R G 7 \\
q N R D W 7\end{array}$ & $\begin{array}{l}7043229 \text { - } \\
7072228 \text { SNPs }\end{array}$ & $\begin{array}{l}13.01-17.74 \\
\mathrm{cM}(3.2-4.43 \\
\text { Mb) }\end{array}$ & $\begin{array}{l}-0.296 \\
-0.145\end{array}$ & $\begin{array}{l}2.16 \\
2.39\end{array}$ & $\begin{array}{l}10.4 \\
11.4\end{array}$ & $\begin{array}{l}2.13 \\
2.22\end{array}$ & B & $\begin{array}{l}q R F W 7 \\
q R D W 7\end{array}$ & $\begin{array}{l}13.01-20.29 \\
\text { cM(3.2-5.1 } \\
\text { Mb) }\end{array}$ & B \\
\hline
\end{tabular}


Table 3.Cont.

\begin{tabular}{|c|c|c|c|c|c|c|c|c|c|c|c|c|}
\hline \multirow[t]{2}{*}{$\mathbf{C h}^{\mathrm{a}}$} & \multirow[t]{2}{*}{ Trait } & \multirow{2}{*}{$\begin{array}{c}\text { Root } \\
\text { QTLs } \\
\text { (Under } \\
\text { Normal } \\
\text { growth) }\end{array}$} & \multirow{2}{*}{$\begin{array}{l}\text { Flanking } \\
\text { Marker/s }\end{array}$} & \multirow{2}{*}{$\begin{array}{c}\text { Flanking } \\
\text { region }\end{array}$} & \multirow{2}{*}{$\begin{array}{l}\text { Add. } \\
\text { Effect }^{\mathrm{b}}\end{array}$} & \multirow[t]{2}{*}{ LOD } & \multirow{2}{*}{$\begin{array}{c}\mathbf{R}^{2} \\
(\%)\end{array}$} & \multirow{2}{*}{$\begin{array}{c}\text { LOD } \\
\alpha=0.05\end{array}$} & \multirow[t]{2}{*}{$\mathbf{D A}^{\mathbf{c}}$} & \multicolumn{3}{|c|}{$\begin{array}{c}\text { Consistent root QTLs under } \\
\text { salinity stress }{ }^{\mathrm{d}} \\
\text { (Gimhan } \text { et al., 2016) } \\
\end{array}$} \\
\hline & & & & & & & & & & QTL & $\begin{array}{l}\text { Flanking } \\
\text { region }\end{array}$ & $\mathbf{D A}^{\mathrm{c}}$ \\
\hline 8 & TRG & $q N T R G 8$ & $\begin{array}{l}8969762- \\
8983572 \text { SNPs }\end{array}$ & $\begin{array}{l}101.22-103.03 \\
\mathrm{cM}(\mathbf{2 5 . 3 0}- \\
\mathbf{2 5 . 7 5} \mathbf{M b})\end{array}$ & 0.301 & 2.67 & 12.7 & 2.47 & $\mathrm{~A}$ & $q R F W 8$ & $\begin{array}{l}111.24- \\
112.24 \\
\text { cM(27.81- } \\
\mathbf{2 8 . 0 6} \mathbf{M b})\end{array}$ & $\mathrm{A}$ \\
\hline 10 & $\begin{array}{l}\text { TRG } \\
\text { RDW }\end{array}$ & $\begin{array}{l}\text { qNTRG10 } \\
q N R D W 10\end{array}$ & RM24894 SSR & $\begin{array}{l}0.0-2.40 \mathrm{cM} \\
(\mathbf{0 . 1 5}-\mathbf{0 . 6 0} \\
\mathbf{M b )}\end{array}$ & $\begin{array}{l}-0.263 \\
-0.097\end{array}$ & 2.81 & $\begin{array}{l}13.3 \\
8.3\end{array}$ & $\begin{array}{l}1.78 \\
1.60\end{array}$ & B & $\begin{array}{l}q R F W 10 \\
q R D W 10\end{array}$ & $\begin{array}{l}0.0-3.16 \\
\mathrm{cM} \\
(\mathbf{0}-\mathbf{0 . 7 9} \\
\mathbf{M b})\end{array}$ & B \\
\hline
\end{tabular}

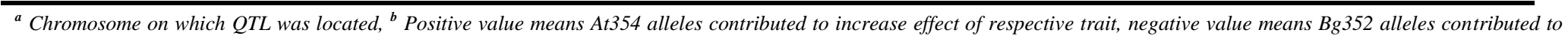
increase effect of respective trait, ${ }^{\circ}$ Donor allele, A-At354 allele, B- Bg352 allele, ${ }^{d}$ Root QTLs related to seedling stage salinity tolerance were identified at 21 days after exposing to salinity stress at EC $12 \mathrm{ds} / \mathrm{m}^{-1}(100 \mathrm{mM})$ under hydroponic system. 


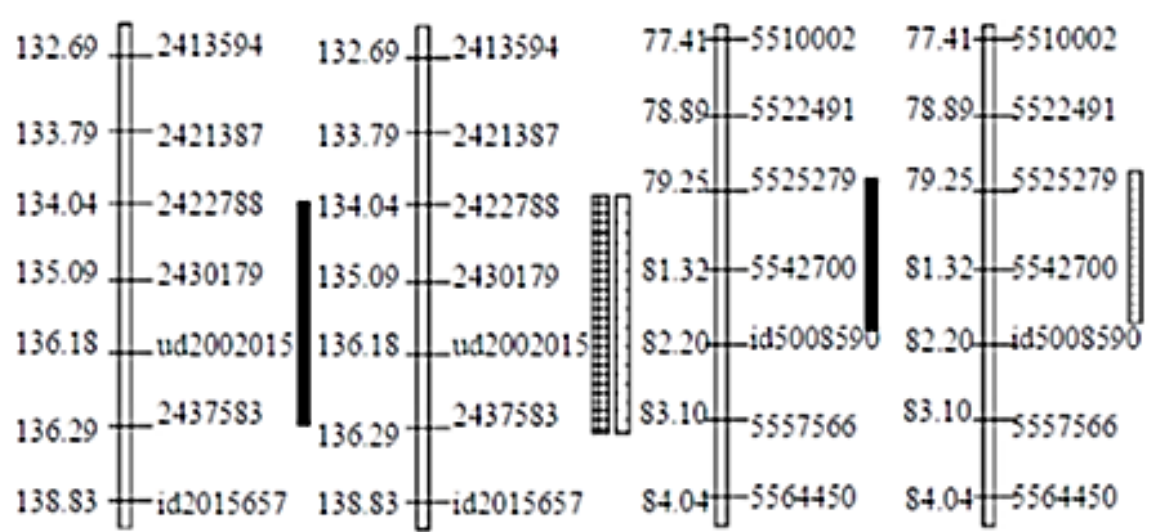

a Chromosome 5 b

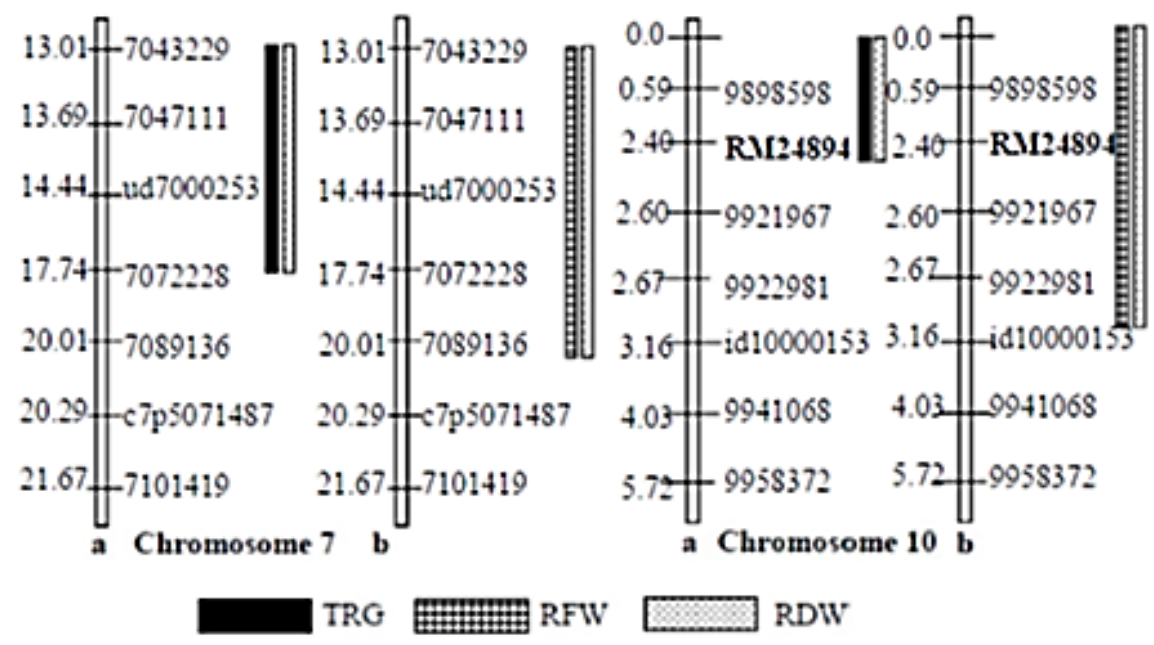

Figure 4. Consistency of the location of root QTLs in rice identified under non-stress and salinity stress environmental conditions

Distances are in centi Morgan (cM).

$a$ - Molecular maps showing root QTLs identified under non-stress condition

$b$ - Molecular maps showing root QTLs identified under salinity stress condition

These two evidences imply that there may be definite causal factors or genes responsible for root traits within the reported location which has been validated by different gemplasm such as Tarome-Molaei (salt-tolerant Iranian variety) $x$ Tiqing (salt-sensitive Iranian variety) and Zhenshan97B (Indica rice variety with shallow rooting) x IRAT109 (Japonica rice variety with deep rooting), in addition to At354x Bg352.

Out of the eight significant QTLs related to root architectural traits revealed under non-stress condition, chromosome $2,4,5$ and 8 possessed positive additive effect indicating the impact 
of At354 alleles for the enhancement of TRG and RDW under non-stress condition (Table 3).The same donor allele has contributed for the co-localized QTLs detected on chromosome 2, 5 and 8 under salinity stress. Rest of the QTLs on chromosome 7 and 10 indicated positive impact of Bg352 alleles in favour of increasing TRG and RDW under non-stress condition while same donor alleles have contributed for the co-localized QTLs detected under salinity stress (Table 3).

The same donor alleles and same genomic locations were detected in some QTLs in both salinity stress and non-stress conditions, confirming the trustworthiness of the flanking region of those putative QTLs, which is worthwhile to be further experimented to find out the candidate genes. Although, RV demonstrated significant difference between At354 and $\mathrm{Bg} 352$, no any QTL was detected on RV under non stress condition. On one hand, this may be due to low variation of RV existed among RILs comparatively to the variation of RDW and TRG. On the other hand, although TRG was not significantly different between parents, five QTLs were detected on TRG probably due to presence of many superior RILs and many inferior RILs, indicating broader spectrum of variation of TRG. Moreover, it was noted that At354 has behaved in favour of TRG and DRW giving arise 4 independent QTLs although we expected many QTLs from the Bg352 parent. This may be due to that the population used in this study was not a randomly selected RIL population, but selected based on the performance of salinity tolerance. Thus, whether more segregants were linked to At354 parent with respect to superior root traits, is not known.

\section{CONCLUSIONS}

This study investigated eight significant QTLs associated with TRG and RDW explaining phenotypic variation ranging from 8.3 to $14.8 \%$ under non-stress hydroponics. These root QTLs were identified between narrow flanking SNP marker intervals on chromosome 2, 4, 5, 7, 8 and 10. Of these eight QTLs, QTLs detected on chromosome 2, 5, 7 and 10, namely qNTRG2, qNTRG5, qNTRG7, qNRDW7, qNTRG10, qNRDW10 were overlapped with another set of root QTLs detected under salinity stress condition, indicating the consistency of the QTLs. Same donor alleles have contributed in both set of QTLs respectively, and these results validated and confirmed the fidelity of the QTLs of TRG and RDW. Further, this study found a closely associated and user friendly SSR marker, i.e. RM24894 to the QTL, $q N T R G 10$ and $q N R D W 10$, in order to facilitate MAB in rice.

\section{ACKNOWLEDGMENTS}

The financial assistance received from Wayamba University Research Grant 2016 (SRHDC/RP/04/16-4) and the National Research Council Research Grant, 2016 (NRC 16016) are gratefully acknowledged.

\section{REFERENCES}

Ahmadi, J. and Fotokian, M. (2011). Identification and mapping of quantitative trait loci associated with salinity tolerance in rice (Oryza sativa) using SSR markers. Iran J. Biotechnol. 9(1), 21-30. 
Bing-Song, Z., Ling, Y., Chuan-Zao, M.,Wei-Ping, Z. and Ping, W.U. (2006). QTLs and candidate genes for rice root growth under flooding and upland conditions. Acta Genetica Sinica. 33(2), 141-151.

Doerge, R.W. and Churchill, G.A. (1996). Permutation tests for multiple loci affecting a quantitative character. Genetics.142, 285-294.

Fukai, S. and Cooper, M. (1995). Development of drought resistant cultivars using physiomorphological traits in rice. Field Crops Res. 40, 67-87.

Gimhani, D.R., Kottearachchi, N.S. and Samarasinghe, W.L.G. (2014). Microsatellite marker based hybridity assessment for salinity tolerance in rice. J Agric. Sci. 9(2), 96-100.

Gimhani, D.R., Gregorio, G.B., Kottearachchi, N.S. and Samarasinghe, W.L.G. (2016). SNP-based discovery of salinity tolerant QTLs in a bi-parental population of rice (Oryza sativa). Mol. Genet. Genomics 291, 2081-2099.

Gowda, V.R.P., Henry, A., Yamauchi, A., Shashidhar, H.E. and Serraj, R. (2011). Root biology and genetic improvement for drought avoidance in rice. Field Crops Res. 122, 1-13.

International Rice Genome Sequencing Project (IRGSP) (2005). The map-based sequence of the rice genome. Nature. 436(7052), 793-800.

Joehanes, R. and Nelson, J. (2008). QGene 4.0, an extensible Java QTL analysis platform. Bioinformatics, 24, 2788-2789.

Lin, H.X., Zhu, M.Z., Yano, M., Gao, J.P., Liang, Z.W., Su, W.A., Hu, X.H., Ren, Z.H. and Chao, D.Y. (2004). QTLs for $\mathrm{Na}^{+}$and $\mathrm{K}^{+}$uptake of the shoots and roots controlling rice salt tolerance. Theor. Appl. Genet. 108(2), 253-260.

Lou, Q., Chen, L., Mei, H., Wei, H., Feng, F., Wang, P., Xia, H., Li, T. and Luo, L. (2015). Quantitative trait locus mapping of deep rooting by linkage and association analysis in rice. J. Exp. Bot. 66(15), 4749-4757.

Mai, C.D., Phung, N.T.P., To, H.T.M., Gonin, M., Hoang, G.T., Nguyen, K.L., D, V.N., Courtois, B. and Gantet, P. (2014). Genes controlling root development in rice. Rice, 7(30), doi: 10.1186/s12284-014-0030-5.

Maiti, R. (2012). Root Responses are Indicators for Salinity and Drought Stress in Crops [on line]. [Accessed on 20.03.16]. Available at http://www.pphouse.org/admin/uploadpdf/IJBSM_Editorial.pdf

Minitab 17 (2010). Statistical Software (2010). [Computer software]. State College, PA: Minitab, Inc.

Sandhu, N., Singh, A., Dixit, S., Cruz, M.S., Maturan, P.C., Jain, R.K. and Kumar, A. (2014). Identification and mapping of stable QTL with main and epistasis effect on rice grain yield under upland drought stress. BMC Genetics, 15(63), doi:10.1186/1471-2156-15-63. 
Steele, K.A., Price, A.H., Shashidhar, H.E. and Witcombe, J.R. (2006). Marker-assisted selection to introgress rice QTLs controlling root traits into an Indian upland rice variety. Theor. Appl. Genet. 112, 208-221.

Tabachnick, B.G. and Fidell, L.S. (2013).Using Multivariate Statistics, Allyn \& Bacon/Pearson Education, California.

Thomson, M.J., De-Ocampo, M., Egdane, J., Rahman, M.A., Sajise, A.G., Adorada, D.L., Tumimbang-Raiz, E., Blumward, E., Seraj, Z.I., Singh, R.K., Gregorio, G.B. and Ismail, A.M. (2010).Characterizing the Saltol quantitative trait locus for salinity tolerance in rice. Rice, 3(2), 148-160.

Thomson, M.J. (2014). High-throughput SNP genotyping to accelerate crop improvement. Plant Breed Biotech. 2(3), 195-212.

Ye, C., Argayoso, M.A., Redon, E.D., Sierra, S.N., Laza, M.A., Dilla, C.J., Mo, Y., Thomson, M.J., Chin, J., Delavin, C.B., Diaz, G.Q. and Hernandez, J.E. (2011). Mapping QTL for heat tolerance at flowering stage in rice using SNP markers. Plant Breeding. 131 (1), 33-41.

Yoshida, S., Forno, D.A., Cock, J.H. and Gomez, K.A. (1976). Laboratory Manual for Physiological Studies of Rice. $3^{\text {rd }}$ ed. International Rice Research Institute, Manila, Philippines. 